\title{
Applicability of Becker's theory of allocation of time in modelling married women's allocation of time between household duties and labour force participation in Zimbabwe.
}

\author{
Clapton Munongerwa*
}

Department of Economics, Midlands State University, Harare, Zimbabwe

${ }^{*}$ Corresponding author: Clapton Munongerwa, clapton.munongerwa@gmail.com

\section{OPEN ACCESS}

Citation: Clapton M. (2016) Applicability of Becker's theory of allocation of time in modelling married women's allocation of time between household duties and labour force participation in Zimbabwe. Open Science Journal 1(1)

Received: $21^{\text {st }}$ March 2016

Accepted: $27^{\text {th }}$ April 2016

Published: $30^{\text {th }}$ April 2016

Copyright: (C) 2016 This is an open access article under the terms of the Creative Commons

Attribution License, which permits unrestricted use, distribution, and reproduction in any medium, provided the original author and source are credited.

Funding: The author(s) received no specific funding for this work

Competing Interests: The author have declared that no competing interests exists.

\section{Abstract:}

With the rise in women participation in labour force and gender equality campaigns on the one hand and cultural norms which characterise women as house makers on the other, most married women often find themselves in a dilemma as to how to allocate their time among competing needs. This paper used a theoretical approach in reviewing the applicability of the proposals of Becker's allocation of time theory to the married women's allocation of time between household duties and labour force participation to the Zimbabwean situation. It was concluded that though the model ignores the cultural norms of assigning household roles to specific gender, it explained to a greater extent the trends observed in which women spend more time in household chores to which they have a comparative advantage as opposed to their male counterparts. The substitution and income effects explained in this model are also applicable to the preferences and patterns of time allocation by married when faced with a change in wages.

Key words: Time Allocation, Becker's Theory, Married Women, Labour force participation 


\section{Introduction}

With the rise in women participation in labour force and gender equality campaigns on the one hand and cultural norms which characterise women as house makers on the other, most married women often find themselves in a dilemma as to how to allocate their time among competing needs. Becker's theory of allocation of time provides a basic theoretical analysis of choice that includes the cost of time on the same footing as the cost of market goods [1].

\section{Objectives}

This paper serves to discuss Becker's theory of allocation of time and the extent to which it models decisions made by married women as they allocate time between household duties and labour force participation.

\section{Methodological issues}

The paper is purely qualitative and was constructed from the vast literature surrounding the Becker's theory and also the knowledge on the participation of married women in labour markets in Zimbabwe. The analysis was prompted by the idea to match economic theory on labour to the situation obtaining in African countries hence the case of Zimbabwe. A general overview of the country approach was used with no specific questionnaires administered to married women.

\section{Becker's Theory}

Becker's Theory assumes that individuals within a family make informed and rational decisions resulting in the attainment of maximum utility satisfaction through combining time and market goods to produce more basic commodities. It also assumes that individuals decide whether or not to participate in the labour market by comparing the value of their time to the value they place on the time spent at home [1][2]. Household duties include such activities like babysitting, cleaning, ironing and cooking to which no direct income is attributed where as labour force participation or market activities involves trading labour for a wage.

According to Becker's Theory, households maximise utility functions of the form $U\left(Z_{1}, \ldots, Z_{m}\right)$. Each commodity $Z_{i}$ is produced by the household using a production function $Z_{i}=f^{(i)}\left(X_{i}, T_{i}\right), i=1, \ldots, I$. Where each $X_{i}$ is a bundle of goods purchased at the vector of prices $p_{i}$ and $T_{i}$ is the amount of time spent at work. The resource constraints $\sum p_{i} y_{i}=I=w T+V$ where $y_{i}$ are goods purchased, $p_{i}$ are their prices, $I$ is the money income, $w$ is the wage rate per unit of time $T_{i}$ and $V$ is the 
amount of unearned income accruing to households [1][3][4]. In these situations, the amount of money income forfeited in doing non-market activities measures the cost of obtaining additional utility.

\section{Applicability of the Model}

\section{Specialisation in Households}

To a greater extent the model better explains the allocation of time by married women in that on average most married women earn less than their husbands and hence they spend more time carrying out household duties. Becker's theory advocates for specialisation and division of labour within households. Assuming that male and female times are perfect substitutes for home production, then it would be more efficient to specialise. The partner with a comparative advantage in domestic production is likely to give up market work altogether and concentrate on domestic duties [1].

Women are generally viewed as having comparative advantage in household duties especially minding after children and thus would rather commit more of their time for that living the market activities for men. This comparative advantage is even greater during the early stages of a child's life and can be indicated for example in their biological ability to breast feed babies. The average earnings of men have over the past years been higher than that of women though some scholars attribute this to discrimination against women [1]. This then according to Becker explains why most women spend more time in household chores compared to labour participation. However according to Maponga and Mushaka, (2015) even in circumstances where women earn more income than their husbands, married women still had a greater proportion of time allocated to household duties though it was not equal to that of those women who were not employed at all.

An increase in labour force participation by women in Zimbabwe has resulted in some instances where the wife will be the sole bread winner, looking after the family including the unemployed husband. This scenario naturally turns the husband to baby sitting and doing household duties whilst the wife is at work. Though the wife may still be involved in some household duties, the majority of these would be carried out by the husband as he will be having lesser opportunity cost for his time.

In Becker's view, 'the member specialising in household skills may enter the labour market part time if the domestic workload permits' [6]. This assertion holds for the Zimbabwean situation where most people's incomes are far much less than the poverty datum line. Married women have been left with no choice than to increase their labour force participation rate so as to complement their husbands' earnings. Married women in farming communities for example, have been engaged in paid piece jobs to help out generating income for their households. 


\section{The Substitution and Income Effect}

According to Becker's substitution effect, increase in wages would at specific levels of income increase married women's participation in labour force at the expense of household duties [2]. In Zimbabwe the increase in wages has seen increased participation of married women in previously male dominated sectors such as mining and manufacturing sectors. An increase in wages increase the opportunity cost of non - market activities and hence household duties would be more expensive. This factor then compels them to trade their labour for money income at the expense of household duties. This also explains the increase in the number of women aiming higher decision making posts which are highly remunerated.

In contrast, the substitution effect will be outweighed by the income effect for higher income levels. An increase in the husband's income may also influence the household to want 'high quality' children which would require more time [2]. This then would result in the married woman devoting much of her time to babysitting since the household can now afford to forgo the income she could have earned from work. In other words, the household would start to invest their time in more time intensive activities owing to their extra income earned.

\section{Critique of the Model}

\section{Cultural Norms}

However, this model fails to account for cultural norms as a factor affecting time allocation decisions by married women. In Zimbabwe women are expected by culture to perform household chores and are socialised from an early stage as such. On the other hand, men are seen as the bread winners and providers for the family and hence have to sell their labour in order to sustain their families. Historically, women would stay at home looking after the kids and doing household duties whilst their husbands were at work. Some would even discriminate the girl child and only empower the boy child through education so as to prepare him to look after his family when he grows up [5].

Based on this cultural background, there have been many cases where even when the married woman has comparative advantage in market activities (earning more money than her husband), she would still commiting relatively more time to household duties. Specialisation which was advocated by Becker does not apply in such circumstances as other forces would be at play. Becker's model would be fully applicable in a Zimbabwean situation if there is a transformation in the way children are socialised.

\section{Substitutes for Household Chores}

Becker's model ignores the use of substitutes for household duties such as house maids and labour saving equipment like automated cookers, dish washing machines and washing machines. The model is only limited to household duties being carried out either by the husband or the wife. The income effect according 
to Becker would result in the married woman committing more time to household duties but this might not be the case since they will be affording house maids and labour saving equipment and hence living more time for work and leisure. However, Korenman et al, (2005) argue that household duties such as child minding do not have good substitutes and would rather be carried out by either of the parents especially the mother.

\section{Possibility of Simultaneity}

Household duties and labour force participation are seen in the model as mutually exclusive. This may not apply in the 21st Century since there have been a great improvement in making the working environment friendlier to nursing mothers. Married women in some jobs can bring their babies to work and leave them in the mother's rooms under the watchful eye of an attendant. This then allows the women to combine nursing and work activities in a sense. At Lafarge Cement Zimbabwe for example, there are mother's rooms which are conducive for women to regularly breast feed and play with their children whilst at work. Many organisations also allow married women to bring their children to workshops especially those workshops held far from their homes for several days.

\section{The Divorce Factor}

The other factor as asserted by Iversen and Rosenbluth, (2003) is the issue of the divorce factor. In the 1950s when this theory was founded, divorce was for example in United States of America considered one in five cases of new marriages but now it is approximately one in two. In light of such statistics, married women, even those with a comparative disadvantage in market activities would want to engage in labour force participation as a precautionary measure in the event of a divorce. They would want to be economically independent and have options outside marriage. In such cases specialisation becomes almost impossible whilst time allocation to market activities becomes a contentious issue.

\section{Conclusion}

In conclusion, the statement that "Becker's theory of allocation of time better models decisions made by married women as they allocate time between household duties and labour force participation" is generally true for most married women. This is clearly explained through the specialisation concept where married women spend more time in household duties relative to males due to their comparative advantage in such activities. The substitution and income effects explained in this model are also applicable to the preferences and patterns of time allocation by married women when faced with a change in wages. The model however ignores the cultural norms of assigning household roles to specific gender. 


\section{Area for Further Study}

The researcher acknowledges the need to quantify the effects of cultural norms, women empowerment campaigns and socialisation have on the labour participation of married women. There is also need to view the actual cause of low women labour force participation rate hence answering the question: " is it because of discrimination or comparative advantage that women relatively spend more time on household chores as compared to the male counterparts. Such recommended studies should be able to differentiate the factors affecting rural married women and urban married women.

\section{References}

1. Chiappori, P. A. and Lewbel, A. (2014) Gary Becker's, "A theory of the allocation of time" Economic Journal, Vol. 125, pp 1-8

2. Korenman, S., Liao, M. and O'Neil, J. (2005) Gender Differences in time use and labour market outcomes, Baruch College and CUNY Graduate Center Conference Draft, December 4, 2005, pp. $1-3$

3. Becker, G. S. (1965) A Theory of the Allocation of Time, The Economic Journal, Vol. 75. No.299

4. Heckman, J. (2014) Introduction to a Theory of the Allocation of Time by Gary Becker, Discussion paper No. 8424, August 2014, pp. 5-8

5. Maponga, T. F. and Mushaka C. (2015) Crux gender inequality in household chores among full time married women aged 20 - 40: Case of Gweru City Zimbabwe, American International Journal of Research in Humanities, Arts and Social Sciences. ISSN [Online] 2328-3696. Available: http://www.iasir.net [22/02/16]

6. Iversen, T. Rosenbluth F. 2003, The Political Economy of Gender: Explaining Cross-National Variations in Household Bargaining, Divorce and the Gender Voting Gap." American Journal of Political Science, Vol. 50, August 2003. 